\title{
DESENVOLVIMENTO SUSTENTÁVEL: CONSIDERAÇÕES ACERCA DO DESENVOLVIMENTO ECONÔMICO VERSUS PASSIVO AMBIENTAL
}

\section{SUSTAINABLE DEVELOPMENT: REFLECTIONS ON ECONOMIC DEVELOPMENT VERSUS ENVIRONMENTAL LIABILITIES}

Junio César Mangonaro ${ }^{1}$

\begin{abstract}
RESUMO: As atividades econômicas empresariais e seus efeitos sobre o meio ambiente são questões mundialmente discutidas, tendo em vista a importância dessas para a coletividade. Assim, visando compensar ou minimizar os impactos ambientais negativos das atividades econômicas potencialmente poluidoras há que se determinar uma legislação específica, disciplinadora de procedimentos tecnológicos e operacionais capazes de eliminar ou reduzir poluentes. Além das normas legais, outras recomendações e propostas, ainda sem regulamentação, estão sendo implementadas no sentido da efetiva responsabilidade e das obrigações quanto à restauração de danos ao ambiente. Sob esta ótica o passivo ambiental vem se incorporando como um instrumento de gestão, uma vez que não pode ser ignorado pelas empresas empreendedoras.
\end{abstract}

Palavras Chave: Direito Econômico; Desenvolvimento Sustentável; Empresa; Passivo Ambiental.

\begin{abstract}
The economic activities and their effects on business environment issues in a worldwide scale are discussed in view of the importance of these to the community. Thus, in order to offset or minimize the negative environmental impacts of economic activity it's necessary to determine an specific legislation, disciplinary procedures and operational technology capable of reducing or eliminating pollutants. Beyond legal requirements, recommendations and other proposals, even without regulation, are being implemented towards the effective responsibility and obligations regarding the restoration of environmental damage. Under that view the environmental liabilities has been incorporated as a management tool, since it can not be ignored by entrepreneurs companies.
\end{abstract}

Keywords: Economic Law; Sustainable development; Company; Environmental liabilities.

\section{INTRODUÇ̃̃̃O}

O presente ensaio diz respeito ao desenvolvimento sustentável e sua relação com a preservação do meio ambiente.

\footnotetext{
${ }^{1} \mathrm{O}$ autor é professor universitário na cidade de Londrina junto a Universidade Norte Parananaense- UNOPAR e Pontifícia Universidade Católica-campus Londrina - PUC-PR, Mestre em Empreendimentos Econômicos, Desenvolvimento e Mudança Social pela Unimar - Universidade de Marília.
} 
Hodiernamente, não como admitir que a atividade empresarial pautada na obtenção de lucro, deixe de respeitar os ditames de uma política ambiental que beneficie toda coletividade, pois como se sabe o Direito Ambiental visa a manutenção do meio ambiente equilibrado para as futuras gerações.

Por ser o meio ambiente questão relativa a toda coletividade as atividades econômicas empresariais e seus efeitos sobre o meio ambiente são questões mundialmente discutidas, pois como se vê não há como manter um meio ambiente equilibrado sem sacrificar, em parte, o desenvolvimento econômico.

Assim, visando compensar ou minimizar os impactos ambientais negativos das atividades econômicas potencialmente poluidoras há que se determinar uma legislação específica, disciplinadora de procedimentos tecnológicos e operacionais capazes de eliminar ou reduzir poluentes. Além das normas legais, outras recomendações e propostas, ainda sem regulamentação, estão sendo implementadas no sentido da efetiva responsabilidade e das obrigações quanto à restauração de danos ao ambiente. Sob esta ótica o passivo ambiental vem se incorporando como um instrumento de gestão, uma vez que não pode ser ignorado pelas empresas empreendedoras.

Este trabalho trás a baila a questão da compatibilização do passivo ambiental com o desenvolvimento econômico, sendo certo que só com a harmonia desses dois itens é que a coletividade poderá desfrutar, futuramente, de um meio ambiente saio e equilibrado.

\section{APONTAMENTOS INICIAIS ACERCA DO DIREITO}

É certo que o objeto do Direito compreende as relações humanas, nos seus mais variados graus. É dado ao Direito os mecanismos necessários para condicionar os comportamentos humanos dentro do que "deve-ser" considerado como viável, bom, para uma certa sociedade, em determinado tempo e espaço.

Numa visão Kelsiana, a compreensão do Direito se dá com a compreensão do chamado hipotético condicional, ou seja, ao Direito é dado a tarefa de regrar as relações humanas por meio de um "dever-ser" modalizado nas estruturas deônticas do permitido, proibido e obrigatório.

A concepção formalista do Direito de Kelsen, para quem o Direito é norma, e nada mais do que norma, se harmoniza com a compreensão da regra jurídica como simples enlace lógico que, de maneira hipotética, correlaciona, através do verbo dever ser, uma conseqüência 
C ao fato F. (REALE, 2002, p. 94) Ocorre, entretanto, que não são todas as relações humanas aptas a aplicação deôntica, na medida em que algumas relações são analisadas apenas na esfera econômica, sociológica, filosófica, mas não jurídica. Trata-se do fato que "não existe no mundo jurídico" (VILA NOVA, 2003, p. 42). Logo, o jurista não deve preocupar-se com a simples existência ou não do fato, mas sim a sua existência jurídica, a sua normatização, a jurisdicização de um "dado-fato".

Assim, a organização de todo o conjunto das relações jurídicas relevantes ao Direito compreende o chamado ordenamento jurídico, que resulta na imperatividade ${ }^{2}$ da norma jurídica, diferenciando cada ramo do direito de acordo com "as diversas situações concretas em que os seres humanos se interrelacionam [...] tendo assim conteúdo de relacionamento familiar, contratual, trabalho, etc" (FONSECA, 2004, p. 03.). Vale dizer que:

A ciência jurídica toma determinados fatos da realidade natural ou social e juridiciza, fazendo incidir normas de valor ou desvalor, impondo sanções ou atribuindo efeito jurídico criador, modificador ou extintivo de direitos. (PETERS, 2000, p. 19)

Neste sentido, sendo o Direito o reflexo dominante de cada época, necessário, pois, averiguar como o conteúdo das normas jurídicas é preenchido ainda, quando levado em consideração o "dado-de fato" ambiental-econômico.

Realiza-se, nesse momento, um corte metodológico, na tentativa de se definir se as relações ambientais são objetos de jurisdicização e, por conseguinte, objeto de análise normativa.

Observe-se, todavia, que toda estrutura econômica está enfocada na questão que permeia o homem, desde os tempos mais antigos, ou seja, a satisfação de necessidades ilimitadas frente o emprego de recursos escassos. Assim, os recursos naturais ganham relevância em um cenário econômico de produção, principalmente, pós Revolução Industrial, ante a possibilidade da jurisdicização para que a atividade econômica opere dentro dos parâmetros da máxima eficiência.

Se a humanidade vive inelutavelmente sob os parâmetros da escassez e se a noção básica de economia é indissociável da existência dos chamados bens escassos, pode-se entender que os bens econômicos são aqueles dotados de utilidade para o homem e cujo suprimento seja escasso. (CARNEIRO, 2003.p. 61)

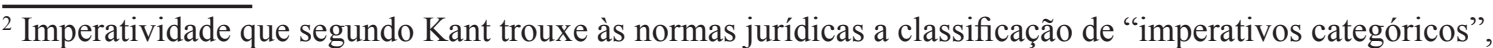
devendo ser observadas as condutas humanas segundo uma certa prescrição normativa, diferenciando-as, assim, das regras atinentes ao campo da Moral.
} 
Assim, o mercado deve encontrar um equilíbrio entre oferta e demanda. Em outras palavras, os mercados constituem uma maneira eficiente de organizar as atividades na economia. Mas, este próprio mercado traz em si algumas respostas que os economistas chamam de "externalidades negativas", ou seja, algumas falhas produzidas, como por exemplo a poluição, a degradação da qualidade ambiental, etc. E, sendo alguns dos recursos ambientais de livre acesso, os agentes econômicos tendem a impor aos demais usuários um custo externo representado por uma perda incompensada em seu bem-estar (CARNEIRO, 2003, p. 65). Por isso, a necessidade de uma legislação ambiental que regule em nome de um "bem estar coletivo" a utilização dos recursos naturais (finitos), estabelecendo-se limites em termos de geração de resíduos, por parte dos agentes econômicos, como abaixo se vê:

[...] a legislação ambiental fixa as normas que instrumentalizam e delimitam a extensão do debate social em torno das tensões dialéticas entre a conveniência econômica de apropriação dos recursos naturais e a necessidade de conservação dos processos ecológicos básicos. É exatamente dentro desses parâmetros definidos pelo ordenamento jurídico que a sociedade expressa suas demandas em relação aos problemas ambientais, discutindo os critérios e as medidas destinadas à melhoria dos índices de qualidade de vida. (FIORILLO, 2004, p. 99).

Imprescindível dizer que o que se busca (como se verifica no próprio texto constitucional) não é a intocabilidade do meio ambiente, mas uma utilização racional e adequada.

Tanto é assim que a Constituição Federal elenca no Art. 170 em seu inciso VI, como princípio basilar da ordem econômica a preservação do meio ambiente, in verbis:

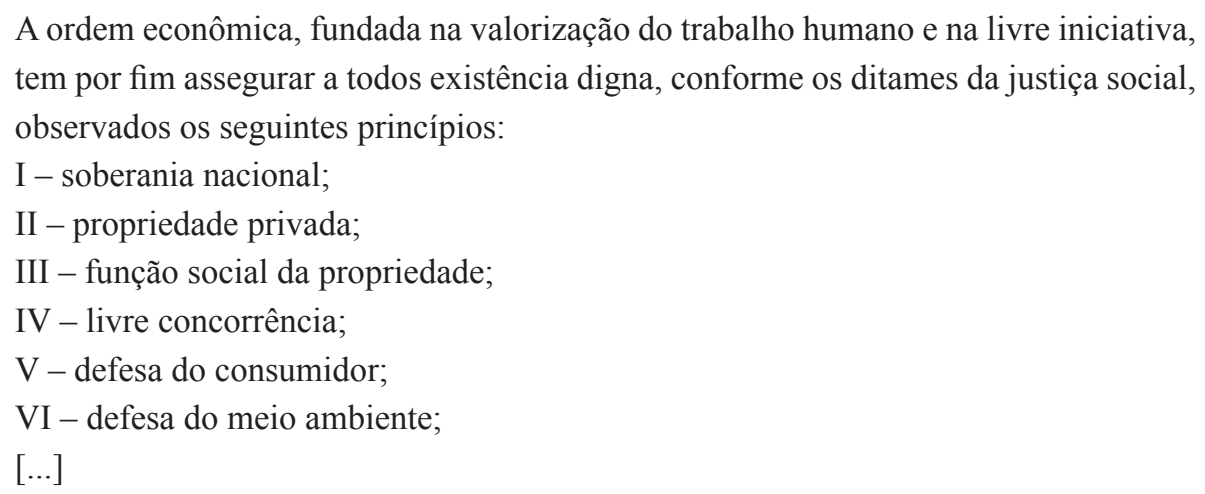

Na lição de Celso Fiorillo:

Ao tratarmos dos princípios relativos ao meio ambiente, tivemos a oportunidade de 
abordar o princípio do desenvolvimento sustentável, o qual se encontra constitucionalmente amparado no art. 225, que prevê o dever da coletividade e do Poder Público de preservar o meio ambiente para presentes e futuras gerações. [...] (FIORILLO, 2004, p. 99).

O simples argumento de que, em princípio, não podemos destruir o bem ambiental - a VIDA -, por força do que determina o Art. 225 da CF (ao contrário dos bens ligados à pessoa humana pela estrutura jurídica da propriedade, em que existe até mesmo a possibilidade de o proprietário destruir a coisa), já é suficiente no sentido de corroborar a natureza jurídica do bem ambiental como única e exclusivamente ao uso comum do povo e, por via de conseqüência, elaborada na ordem econômica do capitalismo visando atender às relações de consumo, mercantis e outras importantes relações destinadas à pessoas humana, dentro de uma nova concepção constitucional criada em 1988, que tem na dignidade da pessoa humana seu mais importante fundamento.

Ademais, a legislação infraconstitucional corrobora na concretização e harmonização entre o desenvolvimento econômico e a proteção ambiental. Segundo Art. $4^{\circ}$, inciso I da Lei n. 6.938/81, o primeiro objetivo da Política Nacional do Meio Ambiente corresponde ao desenvolvimento econômico-social com a preservação da qualidade do meio ambiente e do equilíbrio ecológico.

Assim, modelos de desenvolvimento que não estão sustentados na manutenção da qualidade de vida, são falaciosos, pois é dever de todos a preservação da qualidade ambiental, haja vista que pela letra do Art. 225: "Todos têm direito ao meio ambiente ecologicamente equilibrado, bem de uso comum do povo e essencial à sadia qualidade de vida, impondo-se ao Poder Público e à coletividade o dever de defende-lo e preserva-lo para as presentes e futuras gerações".

Ao mesmo tempo em que a coletividade tem direito a um ambiente sadio, também lhe atribuído a obrigação de preservá-lo e defendê-lo. Desta forma, busca-se uma coexistência harmônica entre a economia e o meio ambiente, pois se deve permitir o desenvolvimento, mas de forma sustentável, planejada, para que os recursos de hoje existentes não se esgotem para as presentes e futuras gerações. Esses argumentos são verídicos, pois como bem se sabe a própria relativização da propriedade é possível quando se busca proteção ambiental. Por outras palavras, o Poder Público está autorizado a limitar sempre que necessário o direito de propriedade quando estiver em questão a preservação do meio ambiente. Na lição de Edis Milaré: 
Nos termos da Constituição, estão desconformes - e, portanto, não podem prevalecer - as atividades decorrentes da iniciativa privada (da pública também), que violem a proteção do meio ambiente. Ou seja, a propriedade privada, base da ordem econômica, deixa de cumprir sua função social - elementar para sua garantia constitucional - quando se insurge contra o meio ambiente. (MILARÉ, 2005. p. 186).

Assim, torna-se cada vez mais atual o desfio de repensar o desenvolvimento econômico e a proteção ambiental sob a ordem jurídica. Resta, pois, neste sentido, analisar os problemas ambientais provenientes de atividades empresariais, também conhecidos como passivo ambiental.

\section{DO PASSIVO AMBIENTAL E SUA INFLUÊNCIA NA ATIVIDADE ECONÔMICA}

A preservação do meio ambiente, através do manejo adequado dos recursos naturais passou a constituir-se numa das preocupações da sociedade moderna, não podendo em nenhuma nação eximir-se de suas responsabilidades, tendo em vista que o meio ambiente apresenta sinais de fraqueza frente as diversas ações destrutivas do homem. Assim, em virtude da escassez dos recursos naturais é necessário que o homem atinja um nível de consciência capaz de modificar o atual estagio de degradação do meio ambiente.

Com a promulgação da Constituição de 1988, com a adoção de princípios básicos de preservação do meio ambiente, surgindo uma conscientização da sociedade, através da inserção de matérias ou disciplinas que tratam da matéria educação ambiental na estrutura curricular dos colégios e universidades, sendo esta possibilidade prevista pelo Art. 225 do Estatuto Constitucional.

Estes e outros elementos contribuíram para que os estudiosos chegassem à conclusão de que os recursos naturais são bens escassos e que é necessário o manejo adequado, principalmente pelos que degradam o meio ambiente com o intuito de obter lucro.

Sem esgotar o tema, deseja-se abordar o passivo ambiental de forma clara, uma vez que este corresponde as dívidas ambientais das empresas, ou seja, representam os danos causados ao meio ambiente, representando, assim, a obrigação, a responsabilidade social das empresas com os aspectos ambientais.

Hodiernamente, o passivo ambiental tem gerado reflexos das mais diversas formas de condução da atividade empresária, ou seja, inviabilizando em alguns casos até mesmo, atos de 
fusão ou incorporação de empresas em razão de seus grandes débitos junto ao meio-ambiente. Ressalte-se que o passivo ambiental funciona como um elemento de decisão no sentido de identificar, avaliar e quantificar posições, custos e gastos ambientais potenciais que precisam ser atendidos a curto, médio e longo prazo.

Vale dizer que em termos contábeis passivo significa obrigação da empresas com terceiros, sendo que tais obrigações, mesmo sem uma cobrança formal ou legal, deve ser reconhecida. Assim, o passivo ambiental representa os danos causados ao meio ambiente, ou seja, a obrigação, a responsabilidade social da empresa com aspectos ambientais.

Nessa proposta, no balanço patrimonial de uma empresa é incluído, através de cálculos estimativos, o passivo ambiental (danos ambientais gerados) e, no ativo (bens e direitos) são incluídos as aplicações de recursos que objetivem a recuperação do ambiente, bem como investimentos em tecnologia de processos de contenção ou eliminação de poluição .

Para Patrícia Mousinho o conceito de passivo ambiental é "o conjunto de obrigações contraídas de forma voluntária ou involuntária, que exigem a adoção de ação de controle, preservação e recuperação ambiental”.

O conceito apresentado pela autora supracitada apresenta dois outros termos interessantes quais sejam: a preservação e a conservação, sendo que o primeiro significa manter intacto os recursos naturais e conservar significa explorar os referidos bens de forma sustentável. Percebe-se que o passivo ambiental constitui-se em uma obrigação imposta ao empresário de não degradar o meio ambiente, mesmo não tendo, o empresário, iniciado suas atividades, pois, constitui-se em um dever ser ou dever-obrigação. A doutrina considera passivo ambiental, diversos atos praticados pelo empresário, principalmente, a obrigação de controle do lançamento de objetos, gases ou rejeitos de qualquer dívida no meio ambiente. Pode ainda ser considerado passivo ambiental a obrigação imposta ao empresário de armazenar e dispor, de forma adequada, os resíduos que produza ou adquira, além da obrigação de recuperação de áreas por ele degradadas, além da imposição de constituir uma reserva de preservação, mesmo que de forma voluntária. Outrossim, não há um conceito jurídico propriamente dito do que deve ser entendido por passivo ambiental. Mas, segundo Edson Luiz Peters e Paulo de Tarso de Lara Pires ensinando o que é passivo ambiental:

É o valor monetário composto basicamente de três conjuntos de itens: o primeiro, composto das multas, dívidas, ações jurídicas (existentes ou possíveis), taxas e im-

${ }^{3}$ KRAEMER, Maria Elisabeth Pereira. Passivo Ambiental. Disponível em $<$ http://ambientebrasil.com.br/composer.php3?base=./gestão/indez.html\&conteudo=/gestao/passivoambiental.html $>$, acesso em 22 de novembro de 2005. 
postos pagos à inobservância de requisitos legais, o segundo, composto dos custos de implantação de procedimentos e tecnologias que possibilitem o atendimento às não conformidades, e o terceiro, dos dispêndios necessários à recuperação de área degradada e indenizada à população afetada. (PETERS, 2000, p. 19).

Ainda, tem-se que dizer que o passivo ambiental representa toda e qualquer obrigação de curto e longo prazo, destinadas única e exclusivamente a promover investimentos em prol de ações relacionadas à extinção ou amenização dos danos causados ao meio ambiente, inclusive percentual do lucro do exercício, com destinação compulsória, direcionado a investimentos na área ambiental.

No entanto, embora nascido nas ciências contábeis, o Direito se apropriou de tal conceito trazendo novos contornos, ou seja, vinculando-se a idéia de responsabilização por práticas, neste caso, danosas ao meio ambiente. Por isso, torna-se impossível uma empresa não ter passivo ambiental, haja vista, conforme acima explicado, que todos, inclusive atividade empresarial, são responsáveis pela proteção do meio ambiente.

Sobre o tema Maria Suely Moreira alega que são obrigações inerentes ao passivo ambiental:

a) controlar o lançamento de efluentes e as emissões atmosféricas;

b) armazenar e dispor adequadamente os resíduos;

c) recuperar uma área degradada

d) obrigação (mesmo voluntária) de preservar uma reserva ecológica, entre outras. (MOREIRA, 2005)

Assim, vê-se que a preservação ambiental e o desenvolvimento social estão ligados pela necessidade do bem comum, haja vista que não se pode admitir indústrias extremamente desenvolvidas, mas com um passivo ambiental que envergonha um país. Hoje, não há como ignorar que o passivo ambiental representa os danos causados ao meio ambiente, bem como a irresponsabilidade da empresa frente aos aspectos ambientais. Outrossim, os passivos ambientais ficaram amplamente conhecidos pela sua conotação mais negativa, ou seja, as empresas que o possuem agrediram significativamente o meio ambiente e, dessa forma, têm que pagar vultosas quantias a título de indenização de terceiros, de multas e para a recuperação de áreas danificadas. Esses gastos não são planejados, por isso, afetam drasticamente qualquer programação de fluxo de disponibilidades, independentemente do porte da organização. Tão alto quanto os custos dos recursos físicos necessários para a reparação dos danos provocados pelas referidas 
situações, ou até mais, são os gastos requeridos para retração da imagem da empresa e de seus produtos, essencialmente, quando tais eventos são alvo da mídia e da atenção dos ambientalistas e ONGs (MOREIRA, 2005).

Contudo, tem-se que dizer que os passivos ambientais não possuem apenas aspectos negativos, pois podem advir de atitudes responsáveis como as decorrentes da manutenção de sistema de gerenciamento ambiental, os quais requerem pessoas para a sua operacionalização. Tais sistemas exigem ainda a aquisição de insumos, máquinas, equipamentos, instalações para funcionamento, o que, muitas vezes, será feito na forma de financiamento direto dos fornecedores ou por meio de instituição de crédito. Esses são os passivos que devem dar origem aos custos ambientais, já que são inerentes à manutenção normal do processo operacional da empresa.

Todavia, não se pode dizer que só aspectos negativos decorrem do passivo ambiental, uma vez que a implementação deste pelas empresas acaba gerando um bem maior, qual seja: a recuperação do meio ambiente pela sociedade. Observa-se que com a dinâmica dos negócios, os passivos ambientais devem ser tratados com muita atenção e devem fazer parte da tomada de decisões das organizações na aquisição de outras empresas, na formação de cluster, nas fusões, nas análises de riscos do negócio, na venda da empresa e na concepção de novos produtos, dentre outras transações pertinentes ao assunto, pois dependendo da situação podem inviabilizar a atividade empresarial no seu todo.

Neste sentido cabe a seguinte posição:

[...] Dentro deste aspecto pode-se analisar o meio ambiente como objeto de um território em relação aos empreendimentos empresariais ali instalados, sendo o meio ambiente, ponto de referência, objeto dos interesses dos empresários, e a partir do exercício das atividades empresariais (industriais, comerciais, e de prestação de serviços), de forma direta, ou através do consumo dos produtos e serviços, pelos consumidores, sendo este de forma indireta, faz surgir o chamado "passivo ambiental", na medida da ocorrência das degradações ambientais.

Os empresários têm que contabilizar o seu passivo, incluindo o saldo negativo dos prejuízos causados ao meio ambiente, mesmo que o empresário adote o princípio do poluidor, pois conforme constante no parágrafo anterior, o passivo pode ser constituído de forma indireta, na medida da fabricação de produtos ou prestação de serviços, pelos empresários, sendo consumidores, surgindo os rejeitos, principalmente, as embalagens dos produtos, quando a estas, por exemplo, não são recicláveis ou os empresários não definem uma política de recolhimentos dos rejeitos, como é o caso das baterias de aparelhos celulares, dos pneus, ou, ainda, das embalagens plásticas dos refrigerantes. (SANTOS, 2005). 
Após essas considerações, pode-se dizer que num primeiro momento o passivo ambiental apresenta-se como a obrigação que possui o empresário de destinar parte de suas preocupações e, conseqüentemente, de seu lucro para medidas preservativas do meio ambiente, sendo que nesta visão há um distanciamento do conceito em relação à essência da palavra passivo, uma vez que os gastos ou a assunção de obrigações pelo empresário para preservação dos recursos naturais especificamente, deveriam ser elementos essenciais e pré-requisitos para a regularização da atividade econômica a ser desenvolvida pelo empresário.

No meio empresarial, os argumentos acima elucidados demonstram que, o termo ou expressão, passivo ambiental, é utilizado de forma indiscriminada, sem explicar-se a sua essência, devido à existência de duas espécies de passivo ambiental, como se vê:

\begin{abstract}
A primeira espécie ou modalidade de passivo ambiental, de ordem legal, não sendo propriamente ambiental, constitui-se a partir da obrigação de reparar ou compensar os prejuízos ou degradações causadas ao meio ambiente, devido ao manejo inadequado dos recursos naturais ou do meio ambiente, motivo pelo qual é chamado de passivo econômico, por materializar-se em uma dívida oriunda de uma reparação de dano ambiental, tendo suas raízes no princípio do poluidor-pagador, em que poderá haver a degradação dos recursos naturais desde que o degradador responda economicamente pelo dano. Este princípio muito embora seja o mais utilizado pela doutrina e pelas políticas públicas de preservação ambiental, não deve ser visto de forma absoluta, pois na grande maioria das vezes não se consegue com precisão a mensuração do dano ambiental, não se conseguindo fixar um quantum reparatório que absolva todos os reflexos da atuação danosa do empresário. A segunda espécie de passivo ambiental é utilizada como sinônimo de degradação do meio ambiente, não possuindo qualquer elemento ou ponto de congruência com o passivo contábil ou com o econômico, por ser equivalente à própria devastação do meio ambiente, entretanto, também se mostra falha esta visão ou entendimento pela dificuldade de mensuração da devastação. (CARNEIRO, 2003, p. 101).
\end{abstract}

No atual conceito do saldo do passivo ambiental não estão incluídas as degradações anteriores à promulgação da Constituição Federal de 1988, pois a escassez dos recursos naturais prejudica o meio ambiente, como também, a empresa que utilizou os recursos naturais, uma vez que, ficando esta impossibilitada de continuar a exercer a sua atividade econômica caso o seu passivo ambiental líquido seja negativo, devido à empresa não ter tomado as cautelas necessárias para a preservação ou manejo adequado dos recursos naturais. Deste modo, as atividades econômicas e seus efeitos sobre o meio ambiente são questões que devem ser amplamente discutidas, pois tem-se que tentar minimizar os impactos ambientais negativos ao máximo, uma vez que a preservação do meio ambiente é necessidade de todos os indivíduos. Aliás, este 
entendimento somente foi possível a partir de uma maior conscientização da sociedade, intensificando a partir de princípios norteadores inseridos na Constituição Federal de 1988.

\section{CONCLUSÃO}

A definição legal de meio ambiente surgiu com o advento da Lei de Política Nacional do Meio Ambiente, segundo a qual o meio ambiente é o conjunto de condições de leis, influencias e interações de ordem física, química e biológica, que permite, obriga e rege a vida em todas as suas formas.

Essa expressão não é uma expressão jurídica, mas sim de outras ciências, da qual o Direito apropriou-se, dando origem ao fenômeno chamado de transposição (ocorre toda vez que a ciência jurídica toma determinados fatos da realidade natural ou social e juridiciza), fazendo incidir norma de valor ou desvalor ao criar, modificar ou extinguir direitos.

O passivo ambiental, na atualidade, se apresenta, como um desafio a ser ultrapassado não apenas pelos empresários, mas por toda a sociedade na medida em que cada cidadão deve ser responsável pelo dano que cause ao meio ambiente, devendo, inclusive, buscar formas de repará-los, além de adotar medidas preventivas. Deve ser assim, pois o meio ambiente é um recurso escasso, devendo ser preservado.

Sob esta ótica, vê-se que o papel do legislador é importantíssimo, pois ele deve estabelecer regras claras, objetivas e de efetividade prática, visando, principalmente, a contabilização dos passivos das empresas, como também, estabelecendo medidas punitivas para quem deixar de contabilizá-los, sendo também necessário uma contribuição significativa das demais ciências, principalmente a ciência contábil, responsável direta pela efetividade e escrituração do passivo ambiental, segundo determinação legal e de conformidade com os regramentos estabelecidos pela Ciência Jurídica.

Sendo assim, apesar da necessidade das medidas apresentadas, no presente trabalho, a maior de todas as providências a ser efetivada, não apenas pelos empresários, mas por toda a sociedade é o oferecimento de um meio ambiente saudável aos indivíduos das futuras gerações, pois destes mesmos recursos deverão se utilizar.

No campo empresarial, a solução para fazer cessar a degradação ambiental é o estabelecimento de políticas de incentivo as empresas não degradadoras do meio ambiente, incentivando, também, os empreendedores que desrespeitem o meio ambiente a investirem em pesquisa, na busca de encontrarem mecanismos capazes não somente de cessar a degradação, 
mas também de recuperar o que já foi degradado. Quiçá a compatibização da ativo e do passivo ambiental, pois só assim conseguir-se-á concretização do ideal de desenvolvimento econômico com o respeito ao meio-ambiente.

\section{REFERÊNCIAS}

CARNEIRO, Ricardo. Direito Ambiental - uma abordagem econômica. Rio de Janeiro: Forense. 2003.

COELHO, Fábio Ulhoa. Curso de direito comercial. revista e atualizada de acordo com o novo Código Civil (Lei n 10.406, de 10.01.2002). São Paulo: Saraiva, v. 1, 2003.

FIORILLO, Celso Antônio Pacheco. Curso de Direito Ambiental Brasileiro. São Paulo: Saraiva, 2004.

FONSECA, João Bosco Leopoldino da. Direito Econômico. Rio de Janeiro: Forense, 2004.

HERCKERT, Werno. Ativo e passivo ambiental. Disponível em: www.gestiopolis.com/canales/ financeira/articulos/64/acpasambi.htm, 2004.

KRAEMER, Maria Elisabeth Pereira. Passivo Ambiental. Disponível em <http://ambientebrasil.com.br/composer.php3?base=./gestão/indez.html\&conteudo=/gestao/passivoambiental. html $>$, acesso em 22 de novembro de 2005,

MAMEDE, Gladston. Direito empresarial brasileiro: empresa e atuação empresarial. São Paulo: Atlas, v. 1, 2004.

MILARÉ, Edis. Direito do Ambiente., São Paulo: RT, 2005.

MOREIRA, Maria Suely. Passivo Ambiental: o conceito em debate. Disponível em $<\mathrm{http}$ :// www.indg.com.br/iso14000/texto3.asp>, acesso em 28 de novembro de 2005.

PETERS, Edson Luiz; PIRES, Paulo de Tarso de Lara. Manual de Direito Ambiental. Curitiba: Juruá, 2000.

REALE, Miguel. Lições preliminares de direito. São Paulo: Saraiava, 2002.

SANTOS, Jonábio Barbosa dos. As empresas e o passivo ambiental. Publicada no Júris Síntese $\mathrm{n}^{\mathrm{o}} 54$, jul/ago 2005.

VILANOVA, Lourival. As estruturas lógicas e o sistema de direito positivo. São Paulo: Revista dos Tribunais, 2003. 